\title{
Optimization and Kinetics of Bioadsorption of Aqueous Potassium Permanganate in Charred Gacao Shells
}

Cyrus Ariel D.R. Fornoles*, Naela V. Delmo, Alvin Manuel M. Traje, Sheryl Lozel B. Arreola, Amelia B. Hizon-Fradejas, Kevinilo P. Marquez

Institute of Chemistry, University of the Philippines Los Baños, College, Laguna 4031

*Author to whom correspondence should be addressed; email: cdfornoles@up.edu.ph

\begin{abstract}
In this study, charred cacao shells were tested for their capability as bioadsorbent for aqueous potassium permanganate. Optimization of adsorption parameters showed that the best amount of adsorbent is $0.5 \% \mathrm{w}$ of cacao biochar/v of $0.005 \mathrm{~N}$ aqueous $\mathrm{KMnO}_{4}$ with a removal efficiency of $98.79 \%$, and the optimum particle size is $212 \mu \mathrm{m}$, with a corresponding removal efficiency of $99.76 \%$. Kinetics studies showed that the adsorption fits a pseudo-first order reaction with $\mathrm{R}^{2}=$ 0.9833. Lastly, the adsorption data fits the Elovich isotherm with $\mathrm{R}^{2}=0.9712$, which strongly suggests a multi-layer chemisorption on a heterogenous surface. Conclusively, the charred cacao shells were found to be effective as an adsorbent of aqueous potassium permanganate. Furthermore, the resulting product of adsorption can be used to study adsorption of other substances due to its multi-layer nature.
\end{abstract}

Keywords: adsorption; cacao shells; potassium permanganate; bioadsorbent

\section{INTRODUCTION}

Cacao (Theobroma cacao L.) is one of the high value crops in the Philippines, with its annual consumption of around 50,000 metric tons. On top of that, it is an important agricultural commodity marketed worldwide, whose demand is projected to reach 500,000 metric tons by 2020 (Department of Agriculture-Bureau of Plant Industry, 2017). Along with the rising demand for cacao beans and their products are the increasing amount of wastes generated through the different processes they undergo. Upon reaching maturity cacao pods are harvested, followed by the removal of the beans and adhering pulp for further processing, such as fermentation and roasting. The cacao bean contains polyphenols such as catechins, proanthocyanidins, and anthocyanins, which gives the bean a red to purple color. Upon roasting, these polyphenols are oxidized, forming high molecular weight tannins (Romero-Cortes et al., 2013). Fermented cacao beans are then 
subsequently used for the manufacture of chocolate and other cacao-based products, while the inedible cocoa pod husk, bean shell, and cocoa mucilage were underutilized and even treated as wastes (Panak Balentic et al., 2018). The residual biomass, still rich in protein, fiber, ash, and phenolics, oftentimes produces foul odors if not properly stored and/or disposed.

Recently, cacao shells were found to have applications in fertilizer and animal feed preparations, but are mainly used as fuel for boilers (Fowler and Coutel, 2017). Moreover, phenolics-rich extracts obtained from cacao shells were found to have applications in biogas production (Mancini et al., 2016). Cacao shells were also utilized as starting material in an adsorption study for the treatment of lead, cadmium, and other metals (Osakwe et al., 2014; Tejada-Tovar et al., 2018)

This study focused on the potential use of processed cacao shells as adsorbent in treating oxidizing wastes, more specifically, potassium permanganate. Mainly used as an antiseptic, potassium permanganate is a highly corrosive and water-soluble strong oxidizing agent, with a lethal adult dose of $10 \mathrm{~g} / \mathrm{kg}$ (Agrawal et al., 2014). One main concern for the disposal of potassium permanganate wastes is its toxicity to aquatic organisms such as fishes, as it is usually used as disinfectant in fish hatcheries. Exposure to 25, 50, 100, 150, and $200 \mathrm{mg} / \mathrm{L}$ potassium permanganate of tilapia eggs could lead to $0 \%$ hatching rate (Hanjavanit et al., 2013). Further studies lead to calculation of the $96 \mathrm{~h}-\mathrm{LC}_{50}$ for Caspian kutum (Rutilus frisii kutum), which is 3.147$3.260 \mathrm{mg} / \mathrm{L}$ and 3.393-3.528 mg/L for small and large fishes, respectively (Nodeh and Hoseini, 2013).

In the academe, potassium permanganate solutions are often used in laboratory experiments in varying concentrations. Over time, a laboratory can accumulate a high volume of wastes, which poses a problem since permanganate is a strong oxidizing agent. The use of modified carbonaceous material was found to effectively remove potassium permanganate from drinking water, seawater, and industrial wastewater (Mahmoud et al., 2016). The development of other materials and procedure is beneficial in order to have a protocol to treat such wastes to prevent its toxicity and minimize its amount in the environment.

Several researches have delved deeper into the use of permanganate as a surface modifier to improve adsorption (Hu et al., 2018, Pang et al., 2015, Mopoung and Bunterm, 2016). A KMnO4modified activated carbon was effective in adsorbing formaldehyde with a pseudo-second order rate reaction ( $\mathrm{Hu}$ et al., 2018). At low $\mathrm{pH}$, activated carbon modified with increasing $\mathrm{KMnO}_{4}$ concentrations were found to have higher percentage removal of aqueous $\mathrm{Cr}$ (VI) compared to the unmodified adsorbent (Pang et al., 2015). Moreover, modification of the carbon obtained from pineapple leaf fibers by potassium permanganate, increased its ferric ion removal efficiency (Mopoung and Bunterm, 2016). These findings strengthen the possibility of developing and utilizing modified adsorbents to become more effective at removing heavy metals and other wastes.

The aim of this study was to optimize the parameters for the adsorption of potassium permanganate in charred cacao shells and to determine the governing mechanism using different adsorption isotherms.

\section{METHODOLOGY}

Materials and Equipment. Charred cacao shells were obtained from Filipinas Oro de Cacao, Inc. on 23 October 2019 as a by-product of their manufacturing process. Potassium permanganate was purchased from JT Baker. The aqueous $\mathrm{KMnO}_{4}$ solution was boiled, filtered and stored in an amber bottle before use. For the equipment, a Shimadzu IR Spirit with a diamond ATR accessory was used for FTIR analysis and the $\mathrm{pH}$ of the solutions were determined using a $\mathrm{pH}$ meter. A 
Shimadzu AA-7000 GFA with a lamp wavelength of $279.5 \mathrm{~nm}, 7.0 \mathrm{~mm}$ burner height at $2.0 \mathrm{~L} / \mathrm{min}$ acetylene and $15.0 \mathrm{~L} / \mathrm{min}$ air, was used for Mn content analysis. A W.S. Tyler R-30050 sieve shaker was used for particle size separation. The analyses were performed in the Analytical Services Laboratory, Institute of Chemistry and E3 laboratory of the College of Engineering and AgroIndustrial Technology, University of the Philippines Los Baños.

Sample preparation. The charred cacao shells were air-dried for 24 hours followed by oven drying at $90^{\circ} \mathrm{C}$ until moisture content is $<1 \%$. The dried biomass was then sieved through an 850 $\mu \mathrm{m}, 425 \mu \mathrm{m}$, and $212 \mu \mathrm{m}$ mesh using a sieve shaker. The separated fractions were weighed to get the percentage of each particle size range.

Characterization of charred cacao adsorbent. The $\mathrm{pH}$ of the charred cacao adsorbent was determined by mixing $0.250 \mathrm{~g}$ with $50.0 \mathrm{~mL}$ distilled water and shaken for two hours. The $\mathrm{pH}$ of the resulting mixture was determined at $28^{\circ} \mathrm{C}$. The FTIR spectra of the charred cacao adsorbent was determined by placing the dried cacao biochar sample directly on the ATR and analyzed for existing functional groups.

Effect of amount of adsorbent. To determine the effect of the amount of adsorbent on the adsorption of $\mathrm{KMnO}_{4}, 0.125,0.250$, and $0.500 \mathrm{~g}$ of the $212-\mu \mathrm{m}$ charred cacao adsorbent were placed in separate Erlenmeyer flasks containing $50.0 \mathrm{~mL} 0.005 \mathrm{~N} \mathrm{KMnO}_{4}$ solution. The flasks were placed in an orbital shaker at $150 \mathrm{rpm}$ for 120 mins under ambient temperature. The mixtures were filtered through a Whattman no. 5 filter paper and the resulting filtrates were analyzed for Mn content using a Flame Atomic Absorption Spectrophotometer (FAAS). Triplicate measurements were done for each sample.

Effect of particle size. To determine the effect of particle size on the adsorption of $\mathrm{KMnO}_{4}$, $0.250 \mathrm{~g}$ of 212,425 , and $850 \mu \mathrm{m}$ of charred cacao adsorbent were placed in separate Erlenmeyer flasks containing $50.0 \mathrm{~mL} 0.005 \mathrm{~N} \mathrm{KMnO}_{4}$ solution. The flasks were placed in an orbital shaker at $150 \mathrm{rpm}$ for 120 mins under ambient temperature. The mixtures were filtered through a Whattman no. 5 filter paper and the resulting filtrates were analyzed for Mn content using FAAS. Triplicate measurements were done for each sample.

Determination of percent removal. The percentages were calculated using equation 1 , where $\mathrm{C}_{\circ}$ is the initial concentration of $\mathrm{KMnO}_{4}$ used and $\mathrm{C}_{\mathrm{e}}$ is the concentration of $\mathrm{KMnO}_{4}$ at equilibrium.

$$
\% \text { removal efficiency }=\left(\frac{C_{o}-C_{e}}{C_{o}}\right) \times 100
$$

(Equation 1)

Determination of kinetics of adsorption and the adsorption isotherm. The kinetics study was done using the optimized and upscaled parameters as described by (Tejada-Tovar et al., 2018). Adsorption rate was monitored by placing $1.50 \mathrm{~g}$ of cacao biochar in a $500-\mathrm{mL}$ Erlenmeyer flask containing $300.0 \mathrm{~mL} 0.005 \mathrm{~N} \mathrm{KMnO}_{4}$ solution. The flasks were placed in an orbital shaker at 150 $\mathrm{rpm}$ for 120 mins under ambient temperature. For the first 30 minutes, 3-mL aliquots were taken at 10-minute intervals. The aliquots were centrifuged, and the supernatant was acidified and diluted 1:10. After 30 minutes, the time interval was changed to 15 minutes until 120 minutes. The diluted aliquots were analyzed for Mn using FAAS.

Both the pseudo first-order and pseudo second-order analyses were used to determine the rate of adsorption, while the adsorption isotherm was determined using the Langmuir, Freundlich, Dubinin-Radushkevich (D-R), Flory-Huggins, Temkin, and Elovich models. 


\section{RESULTS AND DISCUSSION}

Characterization of charred cacao adsorbent. The separation of the charred cacao adsorbent showed that it contains $38.80 \%>850 \mu \mathrm{m}$ particles, $16.06 \% 850-425 \mu \mathrm{m}$ particles, $12.84 \% 425$ $212 \mu \mathrm{m}$ particles, and $32.30 \%<212 \mu \mathrm{m}$ particles. The FTIR spectra of the cacao biochar (Figure 1) showed that the spectrum is similar to that of non-starchy polysaccharides such as lignin due to the $\mathrm{O}-\mathrm{H}$ stretch and aromatic $\mathrm{C}=\mathrm{C}$ stretch (Derkacheva and Sukhov, 2008). This suggests that the cacao biochar has not been fully charred and still contains organic plant materials that may have played a role in the adsorption of $\mathrm{KMnO}_{4}$. Characterization of the cacao biochar showed that it produces an alkali solution of $\mathrm{pH} 10$ when mixed with water. Based on this data, if $\mathrm{KMnO}_{4}$ undergoes chemisorption in the mixture, the resulting product is brown $\mathrm{MnO}_{2}$ solid (see Equation 2). This was consistent with the color change observed in the adsorbent, which changed from black to brown after the allowed time interval.

$$
\mathrm{MnO}_{4(\mathrm{aq})}^{-}+4 \mathrm{H}_{2} \mathrm{O}_{(\mathrm{l})} \rightleftharpoons \mathrm{MnO}_{2(\mathrm{~s})}+2 \mathrm{O}_{2(\mathrm{~g})}+4 \mathrm{H}_{2} \mathrm{O}_{(\mathrm{l})}
$$

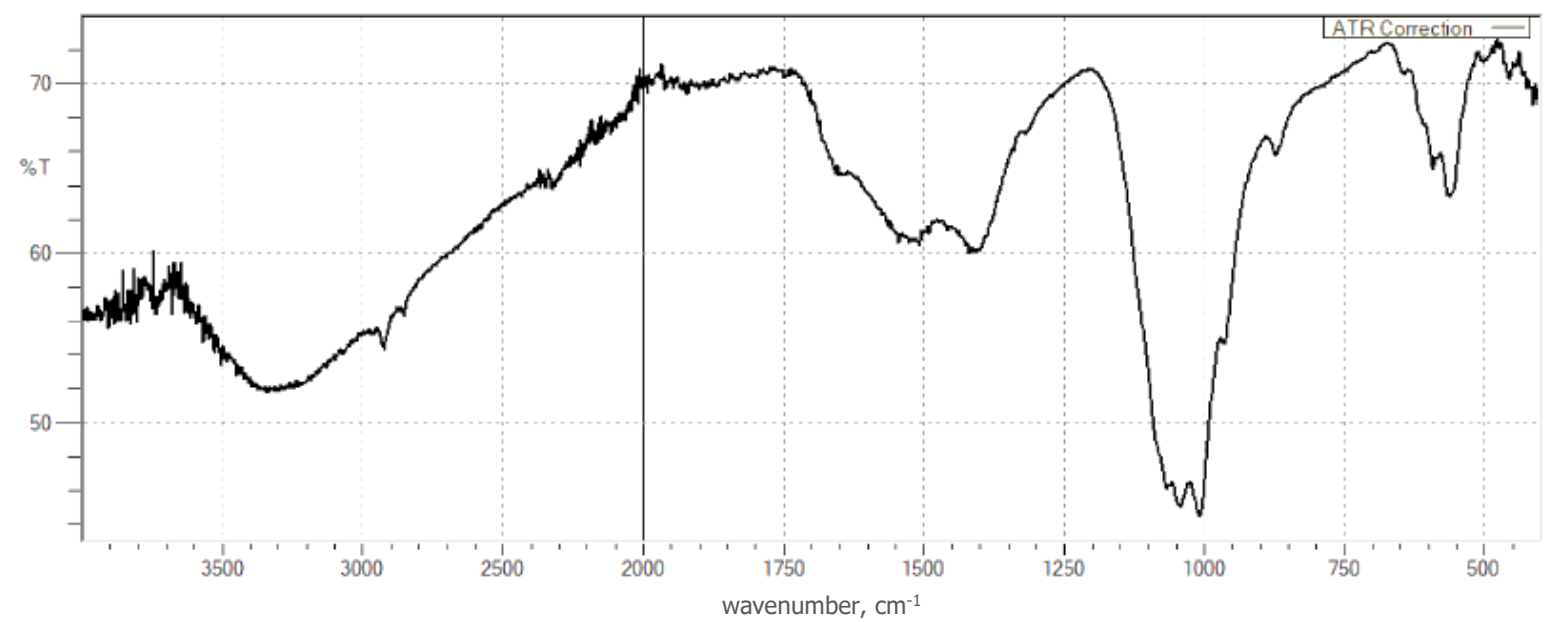

Figure 1. FTIR spectrum of dried cacao biochar.

Effect of amount of adsorbent and particle size on the adsorption of $\mathrm{KMnO}_{4}$. Varying the particle size while keeping the amount of adsorbate constant led to different values of removal efficiency. The results showed that $212 \mu \mathrm{m}$ fraction removed $99.76 \%$ of $\mathrm{KMnO}_{4}$ in the solution while the $425 \mu \mathrm{m}$ and $850 \mu \mathrm{m}$ fractions removed only $94.72 \%$ and $93.85 \%$, respectively. As observed with other studies, a smaller particle size will increase the efficiency of adsorption due to an increase in exposed surface area for the compound of interest to adhere to (Foiresi et al., 2018). On the other hand, the effect of varying mass of adsorbent with a constant concentration of sorbent showed that $0.250 \mathrm{~g}$ of cacao biochar was the optimum amount in removing $\mathrm{KMnO}_{4}$ in a $50.0 \mathrm{~mL}$ of $0.005 \mathrm{~N}$ solution. Using $0.250 \mathrm{~g}$ of cacao biochar removed $98.79 \% \mathrm{KMnO}_{4}$ in the solution while using $0.125 \mathrm{~g}$ and $0.500 \mathrm{~g}$ of cacao biochar removed only $83.80 \%$ and $94.08 \%$, respectively. Although using $0.500 \mathrm{~g}$ of cacao biochar is still considered efficient, it was observed that increasing the amount of cacao biochar resulted in a more colored mixture. This led to the conclusion that $0.05 \mathrm{~g}$ of cacao biochar per $\mathrm{mL}$ of $0.005 \mathrm{~N} \mathrm{KMnO}_{4}$ was the optimum proportion. An increase in mass may be correlated to the increase in the number of particles and consequently, the increase in the number of sites for adsorption. However, it was observed that further increasing the amount did not lead to significant changes in the removal efficiency. The use of cacao shell for $\mathrm{Pb}$ and $\mathrm{Cd}$ adsorption was also consistent with this observation (Osakwe et al., 2014).

Kinetics of adsorption. The amount of $\mathrm{KMnO}_{4}$ remaining in the mixture at certain time intervals for 60 mins was determined to study the effect of contact time on the adsorption. As expected, the removal efficiency increases with time and was found to be complete after 60 mins since there 
was no $\mathrm{Mn}$ detected in the mixture (Figure 2). From this, the adsorption kinetics of $\mathrm{KMnO}_{4}$ using cacao biochar was determined by regressing the data unto linearized pseudo first-order (Equation 3) and pseudo second-order (Equation 4) kinetic equations (Marquez and Ramos, 2019).

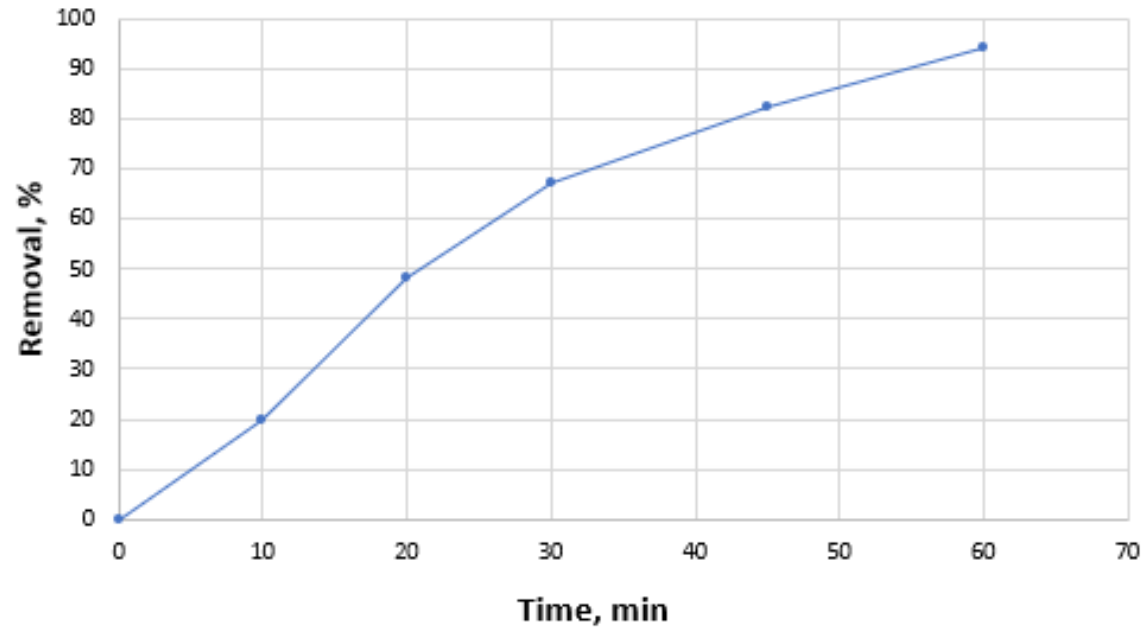

Figure 2. Experimental model of adsorption of $\mathrm{KMnO}_{4}$ using $212 \mu \mathrm{m}$ cacao biochar fraction.

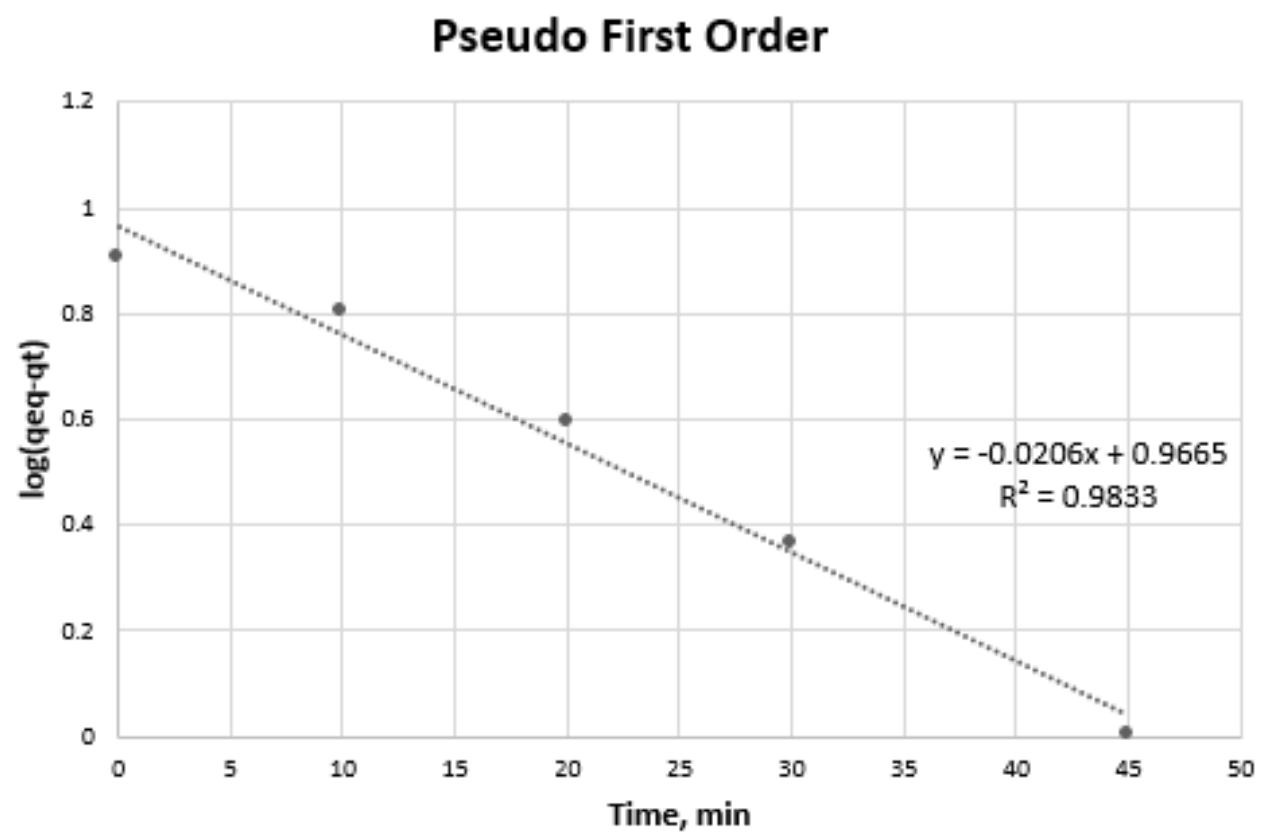

Figure 3. Pseudo first-order model of adsorption of $\mathrm{KMnO}_{4}$ using $212 \mu \mathrm{m}$ cacao biochar fraction. 


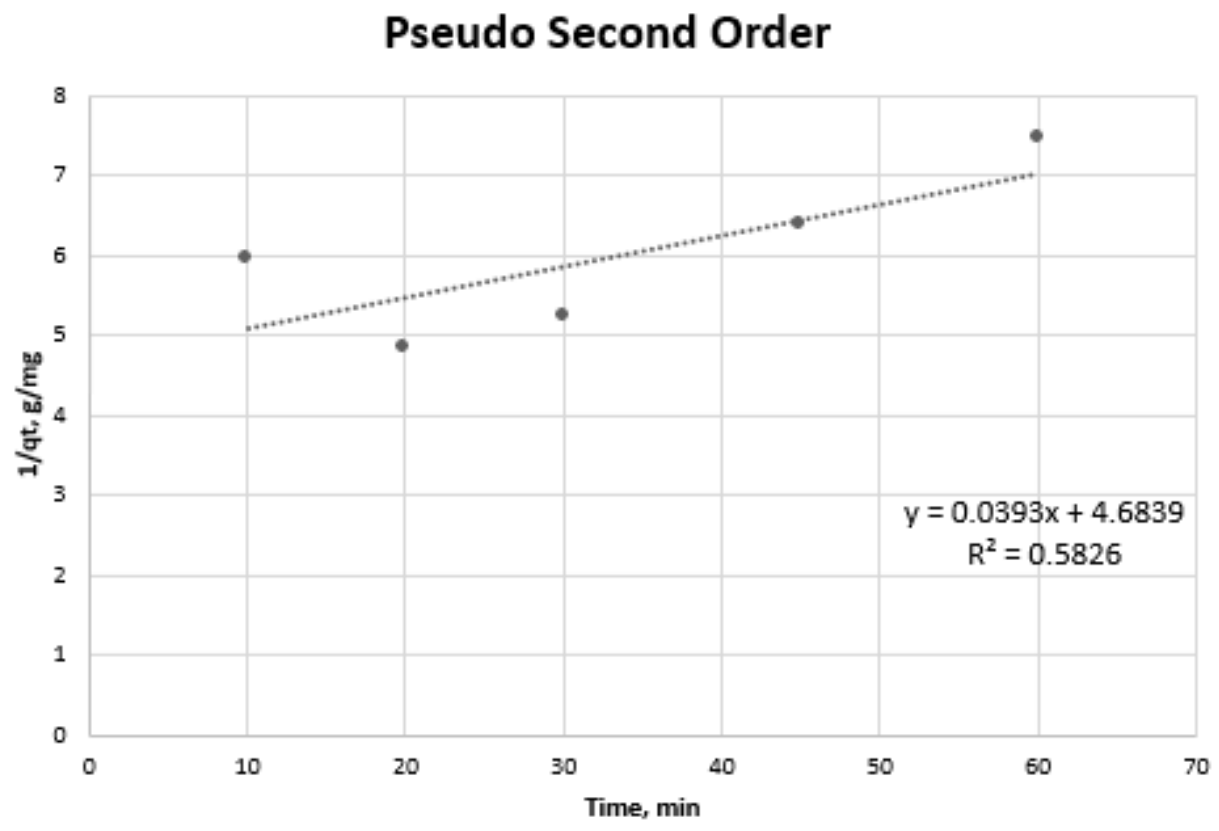

Figure 4. Pseudo second-order kinetic models of adsorption of $\mathrm{KMnO}_{4}$ using $212 \mu \mathrm{m}$ cacao biochar fraction.

Based on the kinetic models as seen in Table 1, the adsorption process follows a pseudo first-order rate equation (Figure 3) with a correlation coefficient $\left(\mathrm{R}^{2}\right)$ of 0.9833 as compared to the pseudo second-order rate equation (Figure 4 ) with a $\mathrm{R}^{2}$ of 0.5826 . A pseudo first-order reaction is a second order reaction whose rate depends on the concentration of two of the reactants. In the experiment, the concentration of $\mathrm{KMnO}_{4}$ was kept constant, so the rate of adsorption process depends on the adsorbent. This is different from the results of Aprilliani and colleagues (2018) where pseudo second-order rate reaction was observed for the adsorption of $\mathrm{KMnO}_{4}$ using coconut shell-derived activated carbon. It can be inferred that biochar follows a different rate compared with activated carbon.

Table 1. Analysis of the kinetics of adsorption of $\mathrm{KMnO}_{4}$ to the cacao biochar.

\begin{tabular}{|c|c|c|}
\hline \multirow{2}{*}{ Parameter } & \multicolumn{2}{|c|}{ Value } \\
\hline & Pseudo-first order analysis & Pseudo-second order analysis \\
\hline Equation & $\begin{array}{c}\log \left(q_{e q}-q_{t}\right)=\left(q_{e q}\right)-\frac{K_{p f} t}{2,303} \\
\text { (Equation 3) }\end{array}$ & $\begin{array}{c}\frac{1}{q_{t}}=\frac{q_{e q}^{2}}{K_{p s}}-\frac{t}{q_{e q}} \\
\text { (Equation 4) }\end{array}$ \\
\hline Slope & -0.020560066 & 0.039254743 \\
\hline Intercept & 0.966474026 & 4.683941008 \\
\hline $\mathrm{q}_{\mathrm{eq}} \mathrm{mg} / \mathrm{g}$ & 9.257080183 & 25.47462875 \\
\hline Equilibrium constant & $\mathrm{K}_{\mathrm{pf}}, \min ^{-1} \quad 0.047349833$ & $\mathrm{~K}_{\mathrm{ps}}, \mathrm{g} \mathrm{mg}^{-1} \mathrm{~min}^{-1} \quad 0.000328983$ \\
\hline Correlation coefficient, $\mathrm{r}^{2}$ & 0.983266251 & 0.582614966 \\
\hline
\end{tabular}

Selection of Appropriate Adsorption Isotherm. Determination of adsorption rates and their corresponding mechanism are important especially in designing adsorption experiments, which could be applied to large-scale treatments of industrial wastes (Foo and Hameed, 2010). Adsorption isotherms models can help predict the mechanism of the adsorption process in terms 
of stability and thermodynamic favorability (Marquez and Ramos, 2019). Given the kinetic parameters of the experiments, the adsorption isotherm model amongst Langmuir, Freundlich, Dubinin-Radushkevich, Flory-Higgins, Temkin, and Elovich were determined. The equations for the different adsorption models are summarized in Table 2, and the corresponding correlation coefficient and mechanism inference are summarized in Table 3. The results showed that Elovich was the isotherm that best fits the adsorption data with a $\mathrm{R}^{2}$ of 0.9712 .

Table 2. Summary of isotherm linearized equations and corresponding terms used in this study. Adapted from Marquez and Ramos, 2020.

\begin{tabular}{|c|c|c|}
\hline Isotherm & Equation & Terms \\
\hline $\begin{array}{l}\text { Langmuir } \\
\text { (Equation 5) }\end{array}$ & $\frac{C_{e}}{q_{e q}}=\frac{1}{b Q_{m}}+\frac{C_{e}}{Q_{m}}$ & $\begin{array}{l}\mathrm{C}_{\mathrm{e}}=\text { equilibrium substrate } \\
\text { concentration } \\
\mathrm{b}=\text { Langmuir constant } \\
\text { (binding affinity) } \\
\mathrm{Q}_{\mathrm{m}}=\text { limiting adsorption } \\
\text { capacity }\end{array}$ \\
\hline $\begin{array}{l}\text { Freundlich } \\
\text { (Equation 6) }\end{array}$ & $\log \left(q_{e q}\right)=\log \left(K_{f}\right)+\frac{\log \left(C_{e}\right)}{n}$ & $\begin{array}{l}\mathrm{K}_{\mathrm{f}}=\text { Freundlich constant } \\
\text { (adsorbent capacity) } \\
1 / \mathrm{n} \quad=\quad \text { adsorption } \\
\text { intensity }(0<1 / \mathrm{n}<1)\end{array}$ \\
\hline $\begin{array}{l}\text { Dubinin-Radushkevic (DR) } \\
\text { (Equation 7) }\end{array}$ & $q_{e q}=\ln \left(X_{f}^{\prime}\right)-K^{\prime} e^{2}$ & $\begin{array}{l}\mathrm{X}_{\mathrm{f}}^{\prime}=\text { adsorption capacity } \\
\mathrm{K}^{\prime}=\mathrm{DR} \text { constant } \\
\mathrm{e}=\text { Polanyi potential, } \\
\mathrm{e}=\mathrm{R} \ln \left(1+1 / \mathrm{C}_{\mathrm{e}}\right)\end{array}$ \\
\hline $\begin{array}{l}\text { Flory-Higgins (FH) } \\
\text { (Equation 8) }\end{array}$ & $\log \left(\frac{\theta}{C_{o}}\right)=\log \left(K_{F H}\right)+m \log (1-\theta)$ & $\begin{array}{l}\mathrm{K}_{\mathrm{FH}}=\mathrm{FH} \text { constant } \\
\theta=\text { degree of surface } \\
\text { coverage } \\
\mathrm{m}=\text { slope }\end{array}$ \\
\hline $\begin{array}{l}\text { Temkin } \\
\text { (Equation 9) }\end{array}$ & $q_{e q}=B \ln \left(A_{t}\right)+\frac{R T}{b} \ln C_{e}$ & $\begin{array}{l}\mathrm{B}=\mathrm{a} \text { constant related to } \\
\text { heat of adsorption } \\
\mathrm{A}_{\mathrm{T}}=\text { Temkin binding } \\
\text { constant } \\
\mathrm{b}=\text { adsorption constant }\end{array}$ \\
\hline $\begin{array}{l}\text { Elovich } \\
\text { (Equation 10) }\end{array}$ & $\ln \left(\frac{q_{e}}{C_{e}}\right)=\ln \left(K_{E} q_{m}\right)-\frac{1}{q_{m}} q_{e}$ & $\begin{array}{l}\mathrm{K}_{\mathrm{E}}=\text { Elovich constant } \\
\mathrm{q}_{\mathrm{m}}=\text { Elovich maximum } \\
\text { adsorption capacity }\end{array}$ \\
\hline
\end{tabular}


Table 3. Evaluation of the correlation coefficient $\left(\mathbf{R}^{2}\right)$ of different adsorption isotherms on the adsorption of $\mathrm{KMnO}_{4}$ using cacao biochar.

\begin{tabular}{|c|c|c|}
\hline Adsorption Isotherm & Correlation coefficient & Inference $^{3}$ \\
\hline Langmuir $^{1}$ & 0.849387332 & dynamic equilibrium \\
\hline Freundlich ${ }^{1}$ & 0.71218519 & adsorbent has a heterogeneous surface \\
\hline Dubinin-Radushkevic (DR) & 0.849690221 & physiosorption dominates \\
\hline Flory-Higgins & 0.867698184 & predicts the spontaneity of adsorption \\
\hline Temkin & 0.867698184 & $\begin{array}{l}\text { predicts if the adsorption process is } \\
\text { exothermic }\end{array}$ \\
\hline Elovich $^{2}$ & 0.971207948 & $\begin{array}{l}\text { chemisorption dominates, multi-layer } \\
\text { adsorption }\end{array}$ \\
\hline
\end{tabular}

The Elovich model assumes that the adsorption sites increase exponentially with adsorption (Ayawei, Ebelegi and Wankasi, 2017). According to this model, mechanism of adsorption is based on chemical reactions which are responsible for adsorption. Therefore, there is an exchange of species on the non-homogeneous surface of the solid, which can be summarized as a multi-layer type of adsorption. This result is consistent with previous kinetic studies of Tejada-Tovar et al (2018) in which cacao shells have heterogenous surfaces, common to agricultural biomasses with complex composition. In addition to that, it supports the theory that the mechanism is chemisorption, where the permanganate (Mn VII) is reduced to manganese dioxide (Mn IV) upon adsorption. Moreover, the isotherm suggests a multi-layer adsorption which could mean that the adsorption of $\mathrm{MnO}_{2}$ makes the material become a better adsorbent.

In the study of Eduah and colleagues (2020), the adsorption of phosphate using cocoa pod husk, corn cob, rice husk, and palm kernel shell biochar was explained using the Elovich model. Another researcher used the Elovich model to explain the adsorption of atrazine and imidacloprid using eucalyptus bark, corn cob, bamboo chips, rice husk, and rice straw biochar (Mandal et al., 2017). The result of this study is consistent with the results of other researchers suggesting that the Elovich isotherm best explains the adsorption models of most agricultural by-product derived biochars.

In the study of Ezuego and Anadebe (2018) where they used animal bone and corn cob-derived activated carbon in removing $\mathrm{KMnO}_{4}$, Freundlich and Langmuir isotherms were observed, which indicates a favorable adsorption for electrostatic interaction between the adsorbent forces and $\mathrm{KMnO}_{4}$. Although physiosorption was the main mechanism of adsorption, the researchers also acknowledged the possibility of slight chemisorption.

Comparing the results of Ezuego and Anadebe (2018) and this study, it can be observed that mechanism of adsorption of the activated carbon is physiosorption while biochar resulted in a combination of both chemisorption and physiosorption. This is because the biochar has not been fully converted into carbon and still contain organic plant materials such as cellulose and lignin. These organic materials may be responsible for the chemical reactions involved during the adsorption process. 


\section{CONCLUSION}

Based on the results, the optimum condition of adsorption involved the $212 \mu \mathrm{m}$ fraction and a proportion of $0.05 \mathrm{~g}$ of cacao biochar per $\mathrm{mL}$ of $0.005 \mathrm{~N} \mathrm{KMnO}_{4}$ solution with a maximum removal of $99.76 \%$ at 60 mins. The adsorption mechanism was found to be pseudo first-order reaction, which states that the reaction rate depends on the concentration of two of the reactants, since it has a higher correlation coefficient $\left(\mathrm{R}^{2}\right)$ of 0.9833 as compared to the pseudo second-order rate equation with a $\mathrm{R}^{2}$ of 0.5826 . The appropriate adsorption isotherm was also determined by fitting the models Langmuir, Dubinin-Radushkevich, Flory-Higgins, Temkin, and Elovich with the data. It was found that Elovich was the best fit amongst the isotherms, which had a $\mathrm{R}^{2}$ of 0.9712. The mechanism of adsorption is a combination of chemisorption and physiosorption, where the permanganate (VII) is reduced to manganese dioxide (IV) which then adsorbs to the cacao biochar. Further study of this is suggested for its application in mixed oxidant wastes and use of the resulting residue as an adsorbent for other wastes.

\section{REFERENCES}

Agrawal VK, Bansal A, Kumar R, Kumawat BL, Mahajan P. Potassium permanganate toxicity: A rare case with difficult airway management and hepatic damage. Indian J Crit Care Med. 2014 Dec; 18(12):819-821. https://doi.org/10.4103/0972-5229.146318

Aprilliani F, Warsiki E, Iskandar A. Kinetic studies of potassium permanganate adsorption by activated carbon and its ability as ethylene oxidation material. IOP Conf Ser: Earth Envi Sci. 2018; 141:012003. https://doi.org/10.1088/1755-1315/141/1/012003

Ayawei N, Ebelegi AN, Wankasi D. Modelling and interpretation of adsorption isotherms. J Chem. 2017 Sept; 2017:3039817. https://doi.org/10.1155/2017/3039817

Department of Agriculture-Bureau of Plant Industry. 2017-2022 Philippine Cacao Industry Roadmap, 2017; pp. 6-8. https://www.da.gov.ph/2017-2022-cacao-and-coffee-industry-roadmaps/

Derkacheva O, Sukhov D. Investigation of lignins by FTIR spectroscopy. Macromol Symp. 2008 May; 265(1):61-68. https://doi.org/10.1002/masy.200850507

Eduah JO, Nartey EK, Abekoe MK, Henriksen SW, Andersen MN. Mechanism of orthophosphate $\left(\mathrm{PO}_{4}-\mathrm{P}\right)$ adsorption onto different biochars. Environ Technol Innov. 2020 Feb; 17: 100572. https://doi.org/10.1016/j.eti.2019.100572

Ezeugo J, Anadebe CV. Removal of potassium permanganate from aqueous solution by adsorption onto activated carbon prepared from animal bone and corn cob. Equatorial J Eng. 2018 Jun; 2018:14-21. https://ssrn.com/abstract $=3197865$

Fioresi F, Vieillard J, Bargougui R, Bouazizi N, Fotsing PN, Woumfo ED, et al. Chemical modification of the cocoa shell surface using diazonium salts. J Colloid Interf Sci. 2017 May; 494:92-97. https://doi.org/10.1016/i.jcis.2017.01.069

Foo KY, Hameed BH. Insights into the modeling of adsorption isotherm systems. Chem Eng J. 2010 Jan; 156(1):2-10. https://doi.org/10.1016/j.cej.2009.09.013

Fowler MS, Coutel F. Cocoa beans: from tree to factory. In: Beckett ST, Ziegler GR, editors. Beckett's Industrial Chocolate Manufacture and Use, $5^{\text {th }}$ edition. Chichester, UK: John Wiley \& Sons, Ltd; 2017. p. 9-49. https://doi.org/10.1002/9781118923597.ch2 
Hanjavanit C, Panchai K, Kitancharoen N, Hatai K. The anti-oomycetic effects of sodium chloride and potassium permanganate and the toxicity of these compounds to tilapia (Oreocbromis niloticus) eggs. Afr J Microbiol Res. 2013 April; 7(18):1852-1857. https://doi.org/10.5897/AJMR12.2212

Hu S-C, Chen Y-C, Lin X-Z, Shiue A, Huang P-H, Chen Y-C et al. Characterization and adsorption capacity of potassium permanganate used to modify activated carbon filter media for indoor formaldehyde removal. Environ Sci Pollut Res. 2018 Aug; 25(28): 28525-28545. https://doi.org/10.1007/s11356-018-2681-z

Mahmoud ME, Yakout AA, Saad SR, Osman MM. Removal of potassium permanganate from water by modified carbonaceous materials. Desalin Water Treat. 2016; 57(33):15559-15569. https://doi.org/10.1080/19443994.2015.1073180

Mancini G, Papirio S, Lens PNL, Esposito G. Effect of $N$-methylmorpholine- $N$-oxide pretreatment on biogas production from rice straw, cocoa shell, and hazelnut skin. Environ Eng Sci. 2016 Nov; 33(11):843-850. http://doi.org/10.1089/ees.2016.0138

Mandal A, Singh N, Purakayastha TJ. Characterization of pesticide sorption behaviour of slow pyrolysis biochars as low cost adsorbent for atrazine and imidacloprid removal. Sci Total Environ. 2017 Jan; 577: 376-385. https://doi.org/10.1016/i.scitotenv.2016.10.204

Marquez KP, Ramos RMCR. Alkali lignin from Talahib grass (Saccharum spontaneum L.) as an adsorbent for chromium (III) and phenolphthalein: Analysis of the adsorption kinetics and mechanism. Kimika. 2019 July; 30(2):17-26. https://doi.org/10.26534/kimika.v30i2.17-26

Mopoung S, Bunterm T. $\mathrm{KMnO}_{4}$ modified carbon prepared from waste of pineapple leaf fiber production processing for removal of ferric ion from aqueous solution. Am J Appl Sci. 2016 June; 13(6):814-826. https://doi.org/10.3844/ajassp.2016.814.826

Nodeh AJ, Hoseini SM. Toxicity of potassium permanganate to Caspian kutum (Rutilus frisii kutum) at two Sizes (1 and 3g). Ecopersia. 2013; 1(3): 291-298. http://ecopersia.modares.ac.ir/article-24$\underline{4064-e n . h t m l}$

Osakwe CE, Sanni I, Sa'id S, Zubairu A. Adsorption of heavy metals from wastewaters using Adonosia digitata fruit shells and Theobroma cacao pods as adsorbents. AU J Technol. 2014 Jul; 18(1): 11-18. http://www.journal.au.edu/au techno/2014/jul14/journal181_article02.pdf

Panak Balentić J, Ačkar Đ, Jokić S, Jozinović A, Babić J, Miličević B, et al. Cocoa shell: A byproduct with great potential for wide application. Molecules. 2018 June; 23(6):1404. https://doi.org/10.3390/molecules23061404

Pang M, Liu B, Kano N, Imaizumi H. Adsorption of chromium (VI) onto activated carbon modified with KMnO4. J Chem Chem Eng. 2015; 9(4):280-287. https://doi.org/10.17265/1934$\underline{7375 / 2015.04 .006}$

Romero-Cortes T, Salgado-Cervantes MA, García-Alamilla P, García-Alvarado MA, del C Rodríguez-Jimenes G, Hidalgo-Morales M, Robles-Olvera, V. Relationship between fermentation index and other biochemical changes evaluated during the fermentation of Mexican cocoa (Theobroma cacao) beans. J Sci Food Agric. 2013 Aug; 93(10):2596-604. https://doi.org/10.1002/jsfa.6088 
Tejada-Tovar C, Lopez-Cantillo K, Vidales-Hernandez K, Villabona-Ortiz A, Acevedo-Correa D. Kinetics and bioadsortion equilibrium of lead and cadmium in batch systems with cocoa shell (Theobroma cacao L.). Contemp Eng Sci. 2018 Apr; 11(23):1111-1120. https://doi.org/10.12988/ces.2018.83100 